\title{
A retórica da qualificação e as controvérsias de rotulagem ${ }^{i}$
}

\author{
Marc Angenot \\ Professor Emérito da Universidade McGill, Canadá. \\ marc.angenot@mcgill.ca
}

Resumo: Este artigo analisa a definição corrente dada à retórica argumentativa em sua relação com a persuasão, desde sua origem grega até a Nova Retórica. O estudo adota uma perspectiva dialógica para compreender a argumentação e se concentra na variedade das situações de confronto das conclusões. Essa redefinição da argumentação implica que cada um dos discursos em oposição constitui um analista do outro, são gêmeos antagonistas. Assim, a argumentação constitui um espaço em que se desenvolvem discursos que trazem respostas contraditórias a uma questão controversa, definindo-se não mais como operadora de persuasão ou de consenso, mas como método de gestão das diferenças de opiniões e de representações. Por fim, o artigo conclui que a teoria das interações observa, além da simples persuasão, fenômenos como a coconstrução das conclusões durante o encontro com o outro, bem como uma função fundamental da argumentação, que é dar nome aos conflitos, permitir a expressão e o aprofundamento das diferenças.

Palavras-chave: Retórica. Argumentação. Persuasão. Pragmadialética.

\begin{abstract}
This article analyzes the current definition given to argumentative rhetoric in its relation to persuasion, from its Greek origin to the New Rhetoric. The study adopts a dialogical perspective to understand the argumentation and focuses on the variety of situations confronting the conclusions. This redefinition of argumentation implies that each of the opposing discourses constitutes an analyst of the other, they are antagonistic twins. Thus, argumentation constitutes a space in which discourses are developed that bring contradictory answers to a controversial question, defining itself no longer as an operator of persuasion or consensus, but as a method of managing differences of opinions and representations. Finally, the article concludes that the theory of interactions observes, beyond mere persuasion, phenomena such as the construction of conclusions during the encounter with the other, as well as a fundamental function of the argumentation, which is to offer words to the conflicts, enabling the expression and the reinforcement of differences.
\end{abstract}

Keywords: Rhetoric. Argumentation. Persuasion. Pragmadialectic.

\footnotetext{
' A Revista EID\&A agradece vivamente a Ruth Amossy pela autorização da publicação desta tradução do original "La rhétorique de la qualification et les controverses d'étiquetage", In: Argumentation et Analyse du Discours, n. 13, 2014. DOI: 10.4000/aad.1787.
} 


\section{Introdução}

Seja no domínio das ciências, seja no da filosofia, ou no das instituições acadêmicas, das ciências sociais e históricas, dos mundos artísticos e literários, por todo lugar e constantemente, polêmicas surgem e controvérsias intelectuais veementes se desencadeiam com frequência, as quais, também muito frequentemente, deixam o Empíreo dos especialistas para chegar à cena pública e se tornarem verdadeiros acontecimentos sociais e políticos. Ora, seria preciso constatar até bem recentemente a ausência em língua francesa de trabalhos de problematização, de discussão das questões, de teorização sobre as controvérsias intelectuais e polêmicas públicas. O livro Apologia da polêmica, de Ruth Amossy (2017), veio, felizmente, preencher em parte esta lacuna. No entanto, a história das grandes controvérsias mantém-se limitada a algumas boas amostras. Ela forma, por outro lado, um setor da história intelectual particularmente bem desenvolvido e academicamente identificado em domínio alemão. Foi necessário, ademais, um pesquisador suíço-alemão, Jürg Altwegg, desenvolver, com erudição, uma pesquisa sobre uma história das polêmicas intelectuais na França do século XVIII, em 1989, na sua obra Republik des Geistes ${ }^{1}$. Existe, sem nenhuma dúvida, numerosos livros e panfletos que são partidários de tal ou tal debate de ideias, mas a abordagem desses debates em história das ideias faz enorme falta em domínio francês.

Em um ensaio em homenagem a Chaīm Perelman, Pierre-André Taguieff propôs um corretivo à retórica consensual do filósofo de Bruxelas, apresentando um aspecto inerente, a seu modo de ver, a qualquer interação retórica: "os elementos disso que eu chamarei, diz ele, uma polemologia discursiva" (TAGUIEFF, 1990, p. 261). Taguieff mantém a polemicidade entre os traços pelos quais a argumentação retórica se distingue da demonstração lógica. É uma emenda essencial. Eu não cessei de trabalhar neste sentido e não é por acaso que são os historiadores das ideias que se reúnem para avançar nesse critério: toda história das ideias políticas faz aparecer continuamente confrontos de teses irreconciliáveis, de diálogos de surdos, de controvérsias intermináveis entre posições defendidas com unhas e dentes.

\footnotetext{
${ }^{1}$ Ver também, entre numerosas outras obras, a querela dos historiadores alemães, Augstein et al (1987).
} 
Ora, ocorre que as ditas controvérsias intelectuais ou públicas, ressurgentes e irreconciliáveis, muitas vezes referem-se apenas à qualificação - no sentido jurídico deste termo - de um fato, de um ato, de um acontecimento ou de um indivíduo, de uma entidade política. É este caso particular, um caso muito comum na realidade, que será o objeto destas poucas páginas. As controvérsias mais amargas e intermináveis referem-se, no mais das vezes, (apenas) sobre as palavras com as quais nós classificamos e designamos, e o amargo debate sobre as categorias e denominações começa rapidamente. Essas "querelas de palavras", com suas questões frequentemente pouco compreensíveis para aqueles que não fazem parte do contexto, são de grande peso, e a defesa por parte de cada um de seu próprio vocabulário e de suas próprias classificações parece ser de vital importância. A "qualificação jurídica" é a operação que permite a aplicação de uma regra de direito ao apreender elementos de fato e inscrevê-los em uma categoria do direito positivo, recorrendo inclusive a precedentes jurisprudenciais. A atribuição de uma qualificação jurídica permite, por sua vez, a aplicação do regime jurídico correspondente, isto é, o conjunto de regras de direitos aplicáveis a uma pessoa, a uma organização, a uma atividade etc. Eu proponho entender este conceito, para além do mundo dos pretores, para aplicá-lo a um fenômeno difuso da vida intelectual e da vida em sociedade: as polêmicas mais intransponíveis não têm, no mais das vezes, outro objetivo senão o da pretensão de classificar de uma forma ou de outra e de nomear sem que haja aparentemente outra questão concreta e prática.

Raciocinar e argumentar é, na mais elementar de suas operações, distinguir, identificar e classificar. Tudo começa em retórica, no discurso social e nas ideologias, dando nomes às coisas, fazendo, por exemplo, com duas palavras, duas entidades distintas daquilo que, segundo os outros, é indissociável, daquilo que forma as duas faces ou as etapas de um único processo. Ou, ao contrário, assimilando sob apenas um termo o que "tudo" deveria distinguir. Ora, nada, nem na linguagem nem na relação de inteligência no mundo, proíbe indubitavelmente de se criar entidades heterogêneas, distinções irracionais e amálgamas falaciosos.

Muitas polêmicas persistentes e amargas só têm - ao menos tecnicamente - uma única definição divergente: um embrião seria uma "pessoa humana"? Com toda certeza, se sua definição da "pessoa humana" engloba o feto desde a concepção. Não se pode refutar, com efeito, uma definição, mas simplesmente lhe opor uma outra. 
Entre as vias metodológicas originais abertas nas ciências humanas, na Alemanha contemporânea, pode-se mencionar os trabalhos de Reinhart Koselleck e de seus discípulos, que desenvolveram uma problemática denominada Begriffsgeschichte, a história conceitual ou semântica histórica². Ora, esta história é indissociavelmente uma história polêmica, uma história de polêmicas. As Grundbegriffe, as categorias fundamentais de uma dada cultura política, apenas evoluem em sucessivas controvérsias que opõem classificações e definições contraditórias.

Eu me limito, nas páginas que se seguem, a circunscrever e ilustrar, sumariamente, o que eu vejo como um vasto domínio de pesquisa, a assinalar problemáticas promissoras e a esboçar uma abordagem e um método.

\section{Três exemplos}

Três exemplos, datados do mesmo dia, recentes, ilustram a frequência do fenômeno e a intensidade das reações que polarizam ordinariamente a esfera pública em dois "campos" armados de seus argumentos unilaterais, e que separam, do mesmo modo, nos campos disciplinares, os intelectuais e os especialistas:

Santiago do Chile (AFP), 4 de outubro de 2013: o Conselho Chileno da Educação Nacional, em resposta a uma demanda de "esclarecimento" da ministra da educação, Carolina Schimdt, recomenda, ao fim de diversos anos de discussões politicamente carregadas e alheias a considerações puramente pedagógicas, que o termo "ditadura" seja substituído nos manuais do ensino médio pelas palavras "regime militar", utilizadas até então para qualificar o regime liderado pelo general Pinochet, entre 1973 e 1990.

Paris, Le Monde, 4 de outubro de 2013: Marine Le Pen, desejosa de melhorar a imagem de seu partido, o Front National, ato que tem se tornado frequente, recusa a etiqueta de "extrema direita" atrelada a este partido, criado por seu pai em 1972, e que ela dirige há três anos. "Trata-se de um termo voluntariamente pejorativo", protesta, de uma "injúria", utilizada para prejudicar, colocando o FN no mesmo saco que o movimento neo-nazista grego, Aurora Dourada. Ela planeja tomar medidas legais para fazer parar o que ela considera uma "insulta" e uma "guerra semântica" contra seu movimento. Vale tudo na guerra!: O Le Monde impavidamente replica no título de seu editorial do dia seguinte: "O Front National, partido de extrema direita". "Digamo-lhes novamente, então, de maneira mais clara", reafirma o editorial: "por sua posição única no tabuleiro de xadrez político francês, assim como por suas ideias e seu projeto, o Front

\footnotetext{
2 A Begriffsgeschichte trabalhou essencialmente as "kulturphilosophischen Grundbegriffe", as palavras-conceito fundamentais da vida cívica e política; ela as estudou durante vários séculos, remontando à Renascença, na Idade Média: as palavras Liberdade, Igualdade e Fraternidade e uma soma de outras palavras semelhantes. Ver, a título de introdução, a coleção sob direção de Hans E. Bödecker (2002).
} 
National é, hoje, como ontem, um movimento de extrema direita". O apelo aos especialistas é solicitado em reforço: "eu considero, como a imensa maioria de meus colegas, que o FN é de extrema direita, por sua história e por seu posicionamento objetivo no campo político", explica o pesquisador Joël Gombin à $\mathrm{AFP}^{3}$. Um deputado socialista, Thierry Mandon, insiste no insulto, lançando mão de uma categoria hiperbólica em acréscimo: o FN é um partido "nacionalfascista"4. Esta polêmica se desenrola no momento em que Marine Le Pen se beneficia das pesquisas de opinião, as quais apresentam uma adesão marcada de uma parte do eleitorado às suas ideias. Aparentemente, a qualificação que a líder do Front National estaria pronta a admitir é a de "direita nacional”.

No caso do Front National (FN), a querela de categorização dura já quarenta anos: é uma dupla controvérsia, ao mesmo tempo pública e intelectual, porque os politólogos não menos discutem entre si, mesmo quando recusam as "rotulações" puramente denunciadoras e injuriosas da polêmica pública. Na vida pública, o FN concentra, há quarenta anos, os ódios e os fantasmas, e incarna, para a esquerda, a ameaça fascista ressurgente, crescente, jamais vencida. Do lado dos doutos, contudo, Pierre-André Taguieff afasta o categorema "[neo]-fascista", tornado vazio de sentido, enquanto considera "extrema direita" não menos vago e demasiado polêmico. Taguieff sustenta, por falta de melhor, "populismo", categoria que ninguém reivindica, porque ninguém jamais poderia reconhecer ou proclamar, seja de direita ou de esquerda: “eu sou populista!”. Contudo, esse categorema que, na esfera pública, funciona como uma rotulagem pejorativa para tudo, permite precisamente a Taguieff e a alguns outros, enquanto politólogos dedicados à serenidade objetiva, rejeitar os ainda pejorativos e vazios "fascista" e "extrema direita". Encontram-se, aqui, dois conflitos de qualificação, um intelectual, outro popular, ao mesmo tempo independentes e que, no entanto, se tocam. Finalmente, Pierre-André Taguieff especifica "nacionalpopulismo" para classificar e rotular o FN, evitando "demonizá-lo" sumariamente. Mas o que ele quer dizer com a preservação - num esforço fraseológico para conferir um significado sereno e objetivo - dessa anteposição "nacional-" que provém das línguas germânicas?

\footnotetext{
${ }^{3}$ Site da France TVInfo, 5/10/2-13. Quanto a Laurent Joffrin, diretor do Nouvel Observateur, ele se diz pronto a ir diante dos tribunais para confirmar o direito de qualificar como ele bem entender: “Marine Le Pen não quer que a gente qualifique o Front National de partido de 'extrema-direita'. No entanto, infelizmente, não vemos outra forma de qualificação. O que há à direita do Front National? Alguns grupúsculos marginais que não assumem nenhum papel na cena eleitoral. Sendo assim, o Front National se situa, evidentemente, sobre a borda extrema do espectro político, como o atesta, a propósito, o seu programa". 17.10.2013 (online)

4 “O FN seria um partido de extrema direita? Não apenas um partido de extrema direita, mas, ainda mais que isso, é um partido nacional-fascista” (Libération, 8 Out. 2013).
} 
Terceira ocorrência, no mesmo dia, de uma qualificação quase-jurídica, que desencadeia controvérsias e contra-qualificações estridentes: o Conselho da Europa estima que a circuncisão dos garotos por motivos religiosos constitui uma "violação da integridade física" de uma criança. Gerou-se reações indignadas por parte da imprensa de Israel, que fala de "racismo", e do Conselho francês do culto muçulmano, que evoca não menos rotineiramente a "islamofobia".

A imprensa francesa desse dia, unânime por exceção, qualifica de "neonazistas" os militantes gregos do partido Aurora Dourada. O Figaro intitula, no dia 4 de outubro de 2013: "Grécia: o chefe dos neonazistas da Aurora Dourada em detenção provisória”. Porém, na Grécia, o Partido da Aliança Popular, $\Lambda \alpha \iota \iota_{\varsigma} \Sigma u \nu \delta \varepsilon \sigma \mu \circ \varsigma$, em contrapartida - irredentista, xenófobo, anti-imigrantes, antissemita - nunca se definiu como tal e rejeita expressamente tal designação.

\section{O empréstimo pelos historiadores de categorias jurídicas}

O direito e a historiografia compartilham de paradigmas fundamentais, a saber, os da busca pela verdade sobre os fatos do passado, e os da investigação, da apresentação de peças à convicção, do testemunho e de sua avaliação (segundo o tipo de jurisprudência que forma a "crítica histórica"), das "provas", enfim, - se é também verdade que os princípios jurídicos não podem ser transferidos tais quais na pesquisa histórica, que as exigências em matéria de prova não são da mesma natureza e que - diferença decisiva, mas nem sempre observada, longe disso - o historiador não se presta a - no fim da reconstituição dos fatos, por mais "incriminadores" que eles sejam - julgar nem formular uma acusação (nem um pedido de absolvição) contra os homens do passado.

A Kolyma foi uma rede de "campos" no mesmo sentido que Buchenwald (ou Treblinka) foram "campos"? Os genocídios dos tasmanianos, dos Sioux e dos índios das planícies, dos armenianos, dos judeus, dos ciganos, dos ucranianos, dos tútsis são, da mesma forma definicional, "genocídios"5? Questão por certo aparentemente jurídica, mas que é também muito debatida por historiadores e politólogos. O massacre dos kulaks pelos bolcheviques foi

\footnotetext{
${ }^{5}$ Ou antes deveria eu proclamar por princípio a "unicidade" da Shoah, como fazem Alain Besançon e diversos outros pensadores? Mas Besançon o faz com argumentos místicos que não entram em diálogo com as vítimas não-eurocêntricas de massacres de massa.
} 


\section{$\mathrm{EI} \square \mathrm{dA}$}

um "genocídio de classe"? A mesma essência apesar de acidentes diferentes, para falar como aristotélicos? Ou esse sintagma "genocídio de classe" é propriamente um absurdo? Trata-se de questões jurídicas efervescentes não menos que historiográficas e eminentemente políticas, acompanhadas de intermináveis controvérsias.

\section{"Genocídio"}

Abordando a proliferação contemporânea, fora dos tribunais, dos argumentos por qualificação jurídica, o seu uso e abuso, devemos abordar a questão conexa, não menos matéria de controvérsia, da extensão da categoria, extensão que deveria conservar as conotações ligadas ao caso típico e ao horror moral que ele inspira. A qualificação jurídica provém da autoridade impessoal da lei, mas esta operação eminentemente técnica reprime um pathos, uma emotividade que tende a ressurgir. Eu tomo, logo, um exemplo eminente e cheio de controvérsias de qualificações jurídicas utilizadas por historiadores, pelos ensaístas, jornalistas, atendo-me, precisamente, à categoria de "genocídio".

A palavra genocídio é um neologismo híbrido, greco-latino, formado em 1944 por Raphael Lemkin, professor de direito americano de origem judiopolonesa, a partir da raiz grega үعvoৎ, "nascimento", "gênero", "espécie”, e do sufixo "-cídio", que vem do latim caedere, "matar". O termo apareceu pela primeira vez no seu estudo Axis Rule in Occupied Europe, em 1944 (capítulo IX), para tentar definir os crimes perpetrados pelos nazistas em relação aos povos judeu, eslavo e cigano, durante a Segunda Guerra Mundial; também os cometidos pelo governo dos jovens-turcos do Império Otomano, em relação aos armênios, durante a Primeira Guerra Mundial; e também os crimes cujas vítimas foram os assírios, no Iraque, em 1933 (LEMKIN, 1944). A perseguição dos ciganos pelos nazistas não foi abordada durante o Processo de Nuremberg, não obstante, é certo que também tenha existido "genocídio" no sentido jurídico então estabelecido.

A categoria jurídica é aplicada a Nuremberg, em 1945, pela Shoah, em seguida retomada e apropriada pelos armênios, ucranianos, pelos sobreviventes (quando houve) dos povos dizimados da América e da 
Australásia ${ }^{6}$, pelos tutsis - ao conservar uma carga emotiva, tal como discutir a pertinência do qualificativo de "genocídio" para o massacre de Srebrenitsa (o assassinato de 8.000 homens e crianças da Bósnia pelo exército da Republika srpska de Radio Mladič $)^{7}$ começaria a se considerar o começo de um negacionismo.

Os governos e seus historiadores oficiais relutam em manter a qualificação de genocídio pelos massacres cometidos pelos seus. A Turquia não nega os assassinatos cometidos durante a Grande Guerra pelo governo jovem-turco (M. Erdogan acaba de apresentar um pouco tarde suas “condolências") mas ela contesta, enormemente, a sua amplitude e rejeita a qualificação. A União Europeia reconheceu, em julho de 1997, o genocídio dos armênios, mas o artigo 312 do Código Penal turco torna passível de cinco anos de prisão qualquer um que evoque publicamente o "pretenso genocídio". Orhan Pamuk, Prêmio Nobel de 2006, foi alvo de ameaças contra sua vida por ter afirmado a um jornal suíço que, entre 1915 e 1917, "um milhão de armênios e 30.000 curdos foram assassinados sobre estas terras". Em fevereiro de 2007, Pamuk, em consequência de ameaças que se sucederam ao assassinato de Hrant Dink, instalou-se nos Estados Unidos. A Assembleia Nacional, na França, adotou, em contraste, em outubro de 2006, um artigo de lei penalizando a negação do genocídio armênio.

Contudo, os historiadores franceses não aplicam de bom grado a seu passado colonial a categoria de "genocídio" a qual os historiadores “indígenas" aplicam, em particular, ao massacre de Sétif, de maio de 1945, com seus 40 mil mortos e aos massacres cometidos pelo exército francês em Madagascar, em 1947, com talvez 100 mil vítimas.

A França multiplicou as leis que impõem ao historiador tais qualificações jurídicas: a Lei Gayssot (1990), promulgada contra os negacionistas da Shoah, foi seguida da Lei sobre o genocídio armênio, o qual eu acabei de mencionar, em seguida pela Lei Taubira sobre o caráter de "crime contra a humanidade" do tráfico negreiro e da escravidão.

A categoria de "genocídio", não a título jurídico mas como quadro explicativo e interpretativo, é aplicada por vários historiadores a diferentes episódios da história da URSS. A questão da qualificação jurídica do

\footnotetext{
${ }^{6}$ Pelo primeiro chefe dos tasmanianos - um dos genocídios totalmente realizados da história colonial, sobre o qual muito se foi escrito na época (mas nada reeditado). Em 1873, Truganimi, a última sobrevivente desses povos aborígenes, foi levada a Hobart. Ela aí morre em 1876.

${ }^{7}$ Seguido da "limpeza étnica" de 30.000 refugiados na região.
} 
Holodomor, a fome de 1932-33 na União Soviética, centrada na Ucrânia, foi objeto de numerosos trabalhos, fundamentados desde então em arquivos, desde o ensaio pioneiro de Robert Conquest, Harvest of Sorrow, em 1986. O francês Nicolas Werth, após ter hesitado, por escrúpulo de método, aceita, a partir de então, a qualificação de genocídio, um "genocídio pela fome”, pelo Holodomor que assolou, segundo as estimativas atrozmente contraditórias dos historiadores, entre 2,61 e 6 milhões de vítimas ucranianas. A fome concomitante no Casaquistão, impulsionada pela política de "sedentarização" deste povo nômade, custou a vida de 1,45 milhão de cazaques, o que é $38 \%$ da população total - esta seria a porcentagem mais elevada de mortos para uma nacionalidade soviética nos anos stalinianos (NAIMARK, 2010, p. 76).

Os massacres dos cossacos e do Kouba, as deportações e dizimações das minorias polonesas, turcófonas e coreanas da URSS, as deportações de massa ulteriores e os massacres dos Tártaros da Crimeia, dos chechenos, dos inguches e de outros povos da Caucásia do Norte ${ }^{8}$, dos Alemães do Volga, dos karatchais, dos balkários, dos kalmyks e dos outros "povos inimigos" na era Stalin são cada vez mais frequentemente, com um esforço de precisão de ordem jurídica e de coleção e confrontação dos fatos, qualificados de "genocídios".

Os livros que concluem pela pertinência da categoria de genocídio(s) para a história da URSS se multiplicam em nossos dias, no entanto eles não são abundantes em francês. Historiador e jurista americano, Norman $M$. Naimark publicou Stalin's Genocides, em 2010. A finalidade de seu ensaio é argumentar, em direto internacional, "que os assassinatos em massa de Stalin nos anos 1930 devem ser classificados como "genocídio"9. O autor examina, sucessivamente, a deskulakização de 1929-31, a fome ucraniana e as campanhas de assassinato contra diversas "nacionalidades" que se sucedem de 1934 à Guerra. Inclui-se, evidentemente, os episódios de assassinato de massa do Grande Terror de 1937-38. O massacre de Katyn, em 1940, deve igualmente ser qualificado de genocídio segundo os historiadores e juristas poloneses. Sobre todos esses assuntos, há agora uma literatura considerável baseada nos arquivos do Kremlin e proveniente, inclusive, de historiadores russos e de outros historiadores do antigo Pacto de Varsóvia.

\footnotetext{
${ }^{8}$ A totalidade das populações chechenas e inguche - meio milhão de homens, mulheres e crianças - foi deportada, em 1944, em alguns dias, nos hoje Cazaquistão e Quirguistão.

9 Ele adiciona: "Este argumento é dificultado pelo fato de que não houve um único ato de genocídio no caso soviético, mas sim uma série de ataques inter-relacionados a 'inimigos de classe' e 'inimigos do povo', metonímias para diversos oponentes do Estado Soviético".
} 


\section{$\mathrm{EI} D \mathrm{dA}$}

\section{Extensão da qualificação. Abuso de linguagem e intimidação}

Como ocorre constantemente em retórica erística, expressões derivadas e cada vez menos fundamentadas juridicamente começaram a proliferar, as quais, de algum modo, lucram com a aura condenatória do conceito inicial. A expressão "genocídio cultural" está empregada de maneira frequentemente negligente para descrever a destruição intencional do patrimônio cultural de um povo. A arabização da vida pública, resultante de sucessivos governos desde o tempo de duas gerações no Marrocos e na Argélia, é assim denunciada por diversos tribunais internacionais, pelos "Amazighs", como um "genocídio cultural” antiberbere.

De "genocídio" derivam diversos neologismos e camadas pseudojurídicas brandidas por várias categorias de supostas vítimas: "etnocídio", que é o mais difundido, denota a destruição da identidade cultural de um grupo, sem destruir fisicamente este grupo. "Linguicídio" seria o ato de "matar" uma língua: o termo é utilizado por Claude Hagège (2001). A França seria, por exemplo, culpada de "linguicídio" em relação ao occitano e outras línguas vernaculares. Entretanto, "genocídio cultural" pode ser entendido neste "caso": nacionalistas bretões acusam a França de "genocídio cultural da língua bretã", no site AlterMedia, em 2 de setembro de 2005. "Democídio" é um termo criado pelo politólogo R. J. Rummel para dispor de um conceito mais abrangente que apenas a definição legal de genocídio. "Etnocídio" é também frequentemente utilizado em relação à destruição pelos "brancos" das culturas dos ameríndios da América do Norte, mas o termo é também invocado, de maneira denunciadora, para a "sinisação" sistemática do Tibete pelo regime de Pequim.

Brigitte Bardot faz saber ao mundo já há vários anos sua indignação diante do massacre pelos caçadores canadenses dos "bebês focas"; é seu direito, mas a Fundação Brigitte Bardot denuncia em seu site um "genocídio" em curso, o que é abusar da linguagem de uma maneira que pode chocar, chocar até mesmo as vítimas e sobreviventes dos "verdadeiros" genocídios. "A caça às focas: genocídio de animais selvagens", título de um outro site "antipele".

Há alguns outros exemplos banais e difundidos com conotação legal. Há alguns anos, a expressão "fazer-se refém/ser tomado como refém" foi utilizada de várias maneiras até a insignificância. "As educadoras do berçário fazem um dia de greve: os pais são feitos reféns". Indivíduos bloqueiam uma ponte por 
vinte minutos: os motoristas são feitos reféns"10, a menos que os usuários da ponte sejam qualificados pela mídia de "vítimas colaterais" do conflito. O Sindicato do Livro francês faz uma dia de greve no dia 6 de fevereiro de 2013, os jornais parisienses não aparecem nesse dia: os mercadores de jornais denunciam em alta voz a "condição de refém" que lhe foi imposta: a fórmula será repetida em ciclos no noticiário das 8 horas. $O$ abuso crescente, por parte da mídia e da web, da qualificação (pseudo-)jurídica estridente e hiperbólica sustenta, evidentemente, um caráter cada vez mais fugaz da informação, em que cada lobista precisa gritar cada vez mais alto para se fazer ouvir e prender a atenção por um breve instante.

Uma violenta polêmica recente ilustrou - de maneira perturbadora para a liberdade acadêmica, submetida à pressão de lobbies estrondosos e bem organizados, indiferentes ao ridículo e à boa fé - a função de intimidação que se aplica hoje em dia ao uso, imposto aos outros sob pena de acusação, de qualificações jurídicas abusivas. Professor na Universidade de Lorient e historiador da escravidão, Olivier Pétré-Grenouilleau é o autor de Tráficos negreiros (2005). Ele se viu atacado, no civil, por um grupo de pressão da França de Além-mar, o "Coletivo DOM", por "contestação de crime contra a humanidade": ele é criticado por ter relativizado e mesmo negado a natureza criminal da escravatura, tendo-a contestado o caráter de "crime contra a humanidade" em uma entrevista publicada pelo Journal du dimanche, de 12 de junho de $2005^{11}$. Pétré-Grenouilleau havia declarado: “os tráficos negreiros não são genocídios, explicando um pouco laboriosamente que o Tráfico não tinha por objetivo exterminar um povo, que o objetivo dos Ocidentais era de preservar a mão-de-obra servil, não de aniquilá-la. Este caso é típico: um grupo de pressão, determinado a fazer o evento, instrumentaliza o aparato legislativo para gritar a perseguição e intimidar um pesquisador que não está a serviço incondicional de suas reivindicações. O Caso Pétré-Grenouilleau foi, para muitos historiadores, escaldados pelo abuso cada vez mais frequente de outras "leis memoriais", a gota que faria transbordar o vaso: tais historiadores difundiram, em dezembro de 2005, uma petição intitulada "Liberdade para a história!", que recebeu o apoio de aproximadamente seiscentos pesquisadores $^{12}$. Essa petição reclama a revogação parcial das diversas leis

\footnotetext{
${ }^{10} \mathrm{http}: / /$ leprofesseurmasque.blogspot.ca/2012/02/les-abus-de-langage.html.

${ }^{11} \mathrm{O}$ presidente do coletivo dos Antilhanos Guianeses-Reunionenses, Patrick Karam, devia anunciar, em 3 de fevereiro de 2006, a retirada da denúncia.

12 www.Iph-asso.fr/index.php?option=com_content\&view=article\&id=2\&ltemid=13\&lang=fr Encontra-se, nesta petição (online) distinções que me parecem pertinentes a assinalar: "A história
} 
relativas à sua área de competência, notadamente a lei Taubira de 2001, que impõe o reconhecimento da escravatura e do tráfico negreiro como "crime contra a humanidade", qualificação, seja ela jurídica ou moral, que não foi contestada por nenhum dos intervenientes. Foi necessário um velho historiador moderado que tinha influência no poder, René Rémond (2006), publicar uma crítica global de todas as legislações encarregadas de impor a Verdade histórica - Quando o Estado se mistura com a história - e reclamar, em nome da profissão de historiador, sua retirada em massa.

\section{Rotulagem e demonização}

Certos conceitos apresentam o mundo "sob uma forma julgada". A expressão é de Roland Barthes, no Grau zero da escritura13: "totalitarismo", "neoliberalismo" etc., de uma certa maneira, com suas categorizações, estes rótulos baseados em idealtipos tudo dizem: se você aceita o vocábulo para qualificar uma opinião, uma teoria, você se predispõe a endossar a culpa e as conclusões que dele decorrem. O procedimento de rotulagem condenatória atribui motu proprio uma autoridade, a aparência de pelos menos uma delegação de autoridade, pelo simples fato de que ele qualifica, de maneira quase-jurídica, a pessoa executora do processo tal como um promotor, e transforma a opinião adversa em uma outra coisa que não uma "simples" opinião: um erro, um delito ou mesmo, em um vocabulário datado que guarda ainda sua importância, uma blasfêmia contra o sagrado cívico e político, alguma coisa, enfim, que se designa à indignação pública. Trata-se de categoremas que são, em si mesmos, uma argumentação completa, ou melhor, que permitem a economia no ato de intimidar. A rotulagem acusadora e "demonizadora" está em progresso em nossos dias à medida que o reino das mídias "quentes" e dos soundbites (aforizações) favorece o ultrajante e desencoraja a rara e espetacular discussão serena e ponderada. A lista de base dos "rótulos" se desenha facilmente: "fascista", "racista", as mais antigas, às quais se juntaram sucessivamente "sexista”, “homofóbico”, “islamofóbico”.

não é a moral. O historiador não possui o papel de exaltar ou condenar, ele explica. A história não é a escrava da atualidade. O historiador não lê o passado por meio de esquemas ideológicos contemporâneos e não introduz, nos eventos de outro tempo, a sensibilidade de hoje. A história não é a memória. O historiador, numa abordagem científica, recolhe as memórias dos homens, compara-as entre si, confronta-as com documentos, objetos, traços, e estabelece os fatos. A história leva em conta a memória, não a ela se reduz. A história não é um objeto jurídico. Em um Estado livre, não pertence nem ao Parlamento, nem à autoridade judiciária o papel de definir a verdade histórica. A política de Estado, ainda que com movida pelas melhores intenções, não é a política da história".

${ }^{13}$ N.T.: No original: Le degré zéro de l'écriture. 


\section{$\mathrm{El} \square \mathrm{dA}$}

Observa-se um aumento de poder desse meio retórico para pôr fim ao debate, condenando violentamente um adversário, o qual testemunha um neologismo de sucesso imediato, “demonização”. "Terrorismo intelectual”, "polícia do pensamento", "nova inquisição" são os "contra-fogo" e as "contrarotulações", frutos da indignação de pessoas visadas pelas demonizações.

\section{“Fascista!"}

Eu volto ao "fascismo" como um caso eminente de "sobre-emprego" e de desperdício de sentido, e como modelo histórico de um fenômeno de bastante notoriedade. O antifascismo de antes da Segunda Guerra legou à esquerda do pós-1945 uma categoria nebulosa que estaria em perpétua expansão, um "fascismo" que se torna o insulto supremo, semeado aos quatro ventos. "Na França, somos todos, ou fomos, o fascista de alguém, constatamos" (MACHEFER, 1974, §1). Pascal Ory, notadamente, incomoda-se com esse crescimento: ele ironiza que, no fim do século 20, os esquerdistas identificam a democracia ocidental ao "fascismo" e ao "nazismo", e seus adversários replicam, qualificando de "fascista" ou de "totalitária" sua retórica da contestação (ORY, 1995, p. 34). A crítica do abuso intimidador do uso de "fascismo" só poderia levar ao julgamento de um antifascismo decretado impostor, manipulado pelos comunistas, processo que começou a ser ensinado, apesar de uma longa intimidação, nos anos 1970. Assistiu-se, desde 1945, isto é, desde a queda dos regimes efetivamente "fascistas", a uma vã "multiplicação de fascismos imaginários". O antifascismo, que se deteriorou ao fim de tamanhos abusos de uso, é reduzido hoje a um "conjunto de atitudes mentais, de representações estereotipadas e de crenças "sloganizadas" que Pierre-André Taguieff apresenta como nocivas à vida pública, assim como absurdas (2007, p. 324, p. 460). Todo regime repressivo é "fascista" para a extrema esquerda exceto, por mais brutais e sanguinários que sejam, aqueles que têm a boa ideia de se pretenderem de esquerda, ou, ao menos, anti-imperialistas, aos quais o perdão é concedido.

Os Sex Pistols cantavam antigamente, com a convicção confusa da juventude, Deus salve a rainha e o seu regime fascista. Para Roland Barthes, desejoso de agradar a juventude de 1968, "a língua é fascista" - amável infantilidade, da qual nos lembramos um pouco - e, para a antipsiquiatria dos anos 1960, que ia de vento em poupa, todo psiquiatra era um "fascista". 


\section{$\mathrm{EI} \square \mathrm{dA}$}

Após muito tempo, os conservadores entenderam o truque e, nos Estados Unidos, desde então, denunciam o melhor dos liberais, os intelectuais de esquerda como os verdadeiros fascistas. Observa-se esta manobra de retorsão no Liberal Fascism de Jonah Goldberg: a esquerda americana não parou, de Roosevelt a Hillary Clinton, de defender princípios "marcadamente semelhantes" àqueles de Hitler e de Mussolini, expõe esta obra de tom acadêmico (GOLDBERG, 2007). No mesmo momento, na França, o secretário de Estado, R. Karoutchi, denuncia, em 2008, os ataques da imprensa de esquerda contra o presidente Nicolas Sarkozy como a expressão de um "fascismo rompante".

Hoje, Endehors.org ataca o "novo fascismo" que é o feminismo radical. Um site ecologista resgatou outros "fascistas" a combater, os Céticos do Aquecimento Global (Global Warming Skeptics), todos os que põem dúvida a questão do aquecimento planetário, contudo www.ecofascism.com retruca tacitamente: “ambientalismo é fascismo!". O categorema, amplamente utilizado, continua a se expandir na internet.

Um outro ativismo ostentatório anti-, o "antirrascismo", apareceu em rápidos progressos nos anos 1980 e foi logo nomeado como "a ascensão de um antifascismo bem cansado" (GAUCHET, 2002, p. 222). Ele também seguiu a tendência da instrumentalização, em todos os níveis, e da perda semântica concomitante. "Racismo" é aplicado, desde então, a toda discriminação alegada, qualquer que lhe seja a natureza, e se esvaziou irreversivelmente de qualquer sentido preciso.

Quanto ao "islamo-fascismo", ele se desenvolveu em nossos dias com alguns bons argumentos comparativos e um grande potencial de anacronismo. Se eu aplico "totalitarismo" ou "fascismo" ao regime ba'asista iraquiano ou ao regime de El-Assad na Síria, eu finjo acreditar que esta rotulagem permite fazer economia, em termos de uma comparação adequada e mais além das circunstâncias geopolíticas incomensuráveis.

\section{Um projeto em curso}

Eu não busco aqui concluir esta investigação; não há lugar aqui para fazê-lo, mas eu quero assinalar que meu trabalho atual ${ }^{14}$ se inscreve nesta problemática da retórica da qualificação e das controvérsias de rotulagem.

\footnotetext{
${ }^{14}$ Este ensaio data do ano de 2014.
} 
Eu publiquei há bastante tempo uma monografia, $A$ imunidade da França em torno do fascismo: meio século de polêmicas historiográficas ${ }^{15}$. Eu procurava, nesse trabalho, reconstituir uma controvérsia acadêmica de longo prazo, e interpretá-la dentro de seu contexto histórico. A polêmica sobre a qual eu trabalhei - polêmica franco-francesa e internacional estendida durante meioséculo, 1954-2005 - versa sobre a existência na França do século 20 o que quer possamos relacionar ao "fascismo" (doutrinas, programas, movimentos, eventos e acontecimentos, regime). Ela é pontuada por debates agudos e ataques violentos, especialmente aqueles que acompanharam, na França, os sucessivos livros do israelense Zeev Sternhell.

Eu expandi minha investigação, em um estudo publicado em 2013, que toma, desta vez, os debates entre historiadores ocidentais desde 1945 sobre o "fascismo genérico" e o "fascismo em tal e tal país"16. "Fascismo" forma um embaraço de definições e de tipologias incompassíveis, e isso bem antes que os historiadores acadêmicos o apreendessem: desde 1922, desde que os popolari, os socialistas e os comunistas italianos exilados começaram a rasgar o significado e a natureza do fenômeno que os expulsou de seu país, desde as infindáveis disputas no seio do Komintern e com os trotskystas e oposicionistas até as controvérsias incessantes entre duas gerações de historiadores dos dois mundos, de 1950 a nossos dias. A compilação de definições e interpretações acadêmicas do fascismo resultou, em inglês, em cinco grandes volumes. Uma sub-controvérsia, entre tantas outras, opõe, por exemplo, os historiadores que, como Ersnt Nolte, apenas concebiam o fascismo em "sua época", da Primeira Guerra Mundial, de seus massacres e da reação à "ameaça" comunista, ou seja, os historiadores para quem o fascismo é de 1914-1945, apenas em continente europeu; e aqueles que, ao mesmo modo que o americano Robert Paxton e o britânico Roger Griffin, pensam que se trata de uma virtualidade persistente em todas as sociedades modernas. Convém ao historiador intelectual não criar, por sua vez, após todos esses, uma definição sincrética a mais de "fascismo" - com vistas a pôr em acordo os Nolte, Sternhell, Griffin, Paxton, Milza, Gentile e tantos outros! -, mas sim lançar luzes sobre essa própria dinâmica de desentendimento, fazer compreender a "lógica" em funcionamento nas controvérsias intelectuais de tal sorte a explicar seu caráter inesgotável e insuperável, e, em alguns aspectos, frutífero.

\footnotetext{
${ }^{15}$ N.T.: L'immunité de la France envers le fascisme: un demi-siècle de polémiques historiennes.

${ }^{16}$ O volume 4 comportará anexos: “Religião, sagrado, dogma, crença" e "Religião civil”.
} 
"Fascismo" é um termo categorial que é histórico em sua totalidade, isto é, não inferido a partir nem do entendimento nem do senso comum, mas que permite reagrupar um conjunto de objetos, neste caso, os regimes políticos que serão dados por essencialmente equivalentes e co-inteligíveis segundo parâmetros que apenas fazem sentido na história. Em outras palavras, não há decisão arbitrária para julgar conclusivamente as razões ditas a favor e contra. Um historiador inglês, Stanley Payne (1995), comparou as definições científicas de "fascismo" de meio-século para cá - definições sucessivamente prejudicadas pelas objeções de um e de outro - a um campo de batalha durante a noite, coberto de carcaças de armas sem uso e abandonadas.

Fascismo, nacional-socialismo e comunismo foram, de forma idêntica ou, ao menos, essencialmente comparável, "totalitarismos"? Aqui, encontra-se uma vasta biblioteca a favor e contra, que eu percorri no volume II de Fascismo, totalitarismo, religião secular: três conceitos para o século 20 (cf. ANGENOT, 2013). "Totalitarismo" é o termo mais disputado do vocabulário político e historiográfico já há um século. "Totalitarismo" tem sido apropriado não desde a Guerra Fria, mas sim desde os anos 1920 por todas as correntes políticas e todas as principais escolas historiadoras - rejeitada, repudiada, reivindicada, argumentada e contra-argumentada, definida e contra-definida, e ela serviu para "qualificar" regimes e assimilá-los - pela indignação, precisamente, de historiadores "antifascistas" para designar o regime bolchevique/staliniano e o regime nazista.

A noção complementar, genealógica, das novas "religiões políticas", destinada a uma luta até a morte, mas tendo as mesmas origens e copiadas umas das outras, convida igualmente ao confronto. As ideologias "totalitárias" do século passado, sejam elas de esquerda ou de direita, criaram "vidas inúteis", legitimaram o assassinato de milhares de miseráveis, conceberam e justificaram o recurso ao terror com vistas a submeter a sociedade a um remodelamento integral. Por qual nome designar a natureza de tais convicções? São esses tipos de crenças extremas, aparentemente diferentes da natureza de outros programas e projetos políticos que, desde 1931, o filósofo católico Waldemar Gurian batizou precisamente de "religiões totalitárias". Inúmeros pesquisadores, não menos em conflito entre eles, identificam, na origem do mal do século, a "sacralização da política", em outros termos, a emergência, a hegemonia e, em seguida, a dissolução de politische Religionen, de Political religions, de religiões políticas ou seculares. $\mathrm{O}$ século 20 teria tido, assim, uma série de guerras de religião. "O nosso tempo 
tem sido por excelência a era das fés políticas, das salvações seculares oferecidas em uma escala nacional ou universal" (KOENKER, 1965, VII). As religiões políticas vermelhas, negras e morenas, teriam sido, como as fanáticas religiões reveladas foram em outro tempo, responsáveis pelos massacres e crimes espalhados pelo século, crimes, como sempre, cometidos em nome do Soberano bem.

No fim dos anos 1930, em Viena, Eric Vœgelin (1938), pensador espiritualista que o mundo francófono "descobriu" com um bom meio-século de atraso, foi um dos primeiros a caracterizar a essência da modernidade como relacionada ao aparecimento e ao progresso de "religiões políticas", elevando, em um mundo privado de transcendência, o que ele nomeava um Realissimum, um ídolo mais-que-real, o Estado, a Produção Econômica, a Ciência, a Raça, o Sangue, a Nação, a Classe. Um terceiro conceito infinitamente controverso atravessa a partir de então o pensamento histórico do século 20, o conceito de "Religião política/religião secular". Ein Gespenst geht um: trata-se de um tipo de espectro conceitual que vem assombrar diversas grandes teorias políticas e históricas sem jamais completamente tomar corpo como uma noção partilhada comumente pelo conjunto dos pesquisadores. Mas é um conceito, o qual certos pesquisadores se valem, sem concordar em tudo, como Normal Cohn, Karl Löwith, Eric Vœgelin, e fazem dele, ao menos, um potente instrumento hermenêutico, um meio de perceber a dinâmica da modernidade sob o ângulo de uma interpretação que não seja auto-justificativa.

O conflito entre três categorias em si é patente: o conceito de "fascismo" (genérico) repousa sobre a ideia de que as ditaduras ultranacionalistas repressoras na Europa, nos anos 1920-40, eram semelhantes entre elas por traços essenciais, mas fundamentalmente diferentes da ditadura bolchevique, com a qual elas estavam em conflito frontal, - o conceito de "totalitarismo" supõe, ao contrário, que elas eram semelhantes ou comparáveis em vários ou mesmo todos os aspectos. Este conceito convida à comparação (sem que esta comparação, que também começa nos anos antes da guerra, imponha o uso deste termo) entre os regimes soviéticos, facista e nazista. Daí os gritos ainda bem-vindos, por uma parte da esquerda europeia, pelo menos, sobre o "amálgama" de totalitarismo, confrontando sob diversos parâmetros - e não assimilando o resto - o malogrado nazismo e o comunismo, supostamente pervertido mas cheio de 
boas intenções, e o conceito de "fascismo", qualquer que seja a força heurística deste conceito próprio ao século 20.

\section{Referências}

ALTWEGG, Jürg. Querelles de français. Paris: Grasset, 1989.

AMOSSY, Ruth. Apologia da polêmica. Coordenação da tradução: Mônica Magalhães Cavalcante. Tradução: Rosalice Botelho Pinto et al. São Paulo: Contexto, 2017.

ANGENOT, Marc. Anarchistes et socialistes: trente-cinq ans de dialogue de sourds. Montréal: Discours social, 2003.

. Rhétorique de l'anti-socialisme. Essai d'histoire discursive, 1830-1914. Québec: Presses de l’Université Laval, 2004.

. La parole pamphlétaire: contribution à la typologie des discours modernes. Paris: Payot /Rivages, 2005 [1982]. Nuits, 2008.

. Dialogues de sourds. Traité de rhétorique antilogique. Paris: Mille et une . L'immunité de la France envers le fascisme: un demi-siècle de polémiques historiennes. Suivi de: Le fascisme dans tous les pays. Montréal: Discours social, 2009.

. Fascisme, totalitarisme, religion séculière: trois concepts pour le XXe siècle. Montréal: Discours social, 2013.

AUGSTEIN, Rudolf et al. Historikerstreit: die Dokumentation der Kontroverse und die Einzigartigkeit der nationalsozialistischen Judenvernichtung. München: Piper, 1987.

BARTHES, Roland. Le degré zéro de l'écriture suivi de Nouveaux essais critiques. Paris: Seuil, 1953.

BÖDECKER, Hans E. Begriffsgeschichte, Diskursgeschichte, Metapherngeschichte. Göttingen: Wallstein, 2002.

BRUNETEAU, Bernard. Le totalitarisme. Origines d'un concept, genèse d'un débat, 1930-1942. Paris: Cerf, 2010.

CONQUEST, Robert. Harvest of Sorrow: Soviet Collectivization and the TerrorFamine. New York: Oxford University Press, 1986.

GAUCHET, Marcel. La démocratie contre elle-même. Paris: Gallimard, 2002.

GOLDBERG, Jonah. Liberal Fascism: The Secret History of the American Left, From Mussolini to the Politics of Change. New York: Doubleday, 2007. 
$\mathrm{EI} \square \mathrm{dA}$

Revista Eletrônica de Estudos Integrados em Discurso e Argumentação, Ilhéus, n. 18, abr. 2019.

GUILLAMOU, Jacques. Discours et événement. L'histoire langagière des concepts. Besançon: Presses Universitaires de Franche-Comté, 2006.

GURIAN, Waldemar. Der Bolschewismus: Einführung in Geschichte und Lehre. Freiburg i. B.: Herder, 1931.

. Bolschewismus als Weltgefahr. Luzern: Vita nova, 1935.

HAGÈGE, Claude. Halte à la mort des langues. Paris: Odile Jacob, 2000.

KOENKER, Ernest Benjamin. Secular Salvations: The Rites and Symbols of Political Religions. Philadelphia: Fortress Press, 1965.

KOSELLECK, Reinhart. The Practice of Conceptual History: Timing History, Spacing Concepts. Foreword by Hayden White. Stanford: Stanford University Press, 2002. [Reunião de diversos ensaios teóricos traduzidos em inglês].

1979.

(Ed.). Historische Semantik und Begriffsgeschichte. Stuttgart: Klett-Cotta,

LEMKIN, Raphael. Axis Rule in Occupied Europe: Laws of Occupation, Analysis of Government, Proposals for Redress. Washington: Carnegie Endowment for International Peace, Division of International Law, 1944.

MACHEFER, Philippe. Ligues et fascismes en France. 1919-1939. Paris: PUF, 1974.

MICHELI, Raphaël. Les querelles de mots dans le discours politique: modèle d'analyse et étude de cas à partir d'une polémique sur le mot "rigueur". Argumentation et Analyse du Discours, 10, 2013.

MOIRAND, Sophie; PORQUIER, Rémy. De l'éthique de la nomination à l'éthique de l'interprétation: autour du mot "otage" et de quelques autres. In: DELAMOTTELEGRAND, Régine; CAITUCOLI, Claude (Éds.). Morales langagières. Autour de propositions de recherche de Bernard Gardin. Rouen: Presses des Universités de Rouen et du Havre, 2008. 139-154.

NAIMARK, Norman. Stalin's Genocides. Princeton: Princeton UP, 2010.

NOLTE, Ernst. Der Faschismus in seiner Epoche. Action francaise - Italienischer Faschismus - Nationalsozialismus. München: Piper, 1963.

ORY, Pascal. La France allemande. Paris: Gallimard, 1995.

PAYNE, Stanley. A History of Fascism, 1914-1945. London: UCL, 1995.

PÉTRÉ-GRENOUILLEAU, Olivier. Traites négrières, essai d'histoire globale. Paris: Gallimard, 2005.

RÉMOND, René. Quand l'Etat se mêle de l'histoire. Entretiens avec François Azouvi. Paris: Stock: Les essais, 2006. 
RICHTER, Melvin. The History of Political and Social Concepts: A Critical Introduction. New York; Oxford: Oxford University Press, 1995.

TAGUIEFF, Pierre-André. L'argumentation politique. Analyse du discours et Nouvelle rhétorique. A la mémoire de Chaïm Perelman, 1912-1984. Hermès, n. 8-9, p. 261- 286, 1990.

. Les contre-réactionnaires. Le progressisme entre illusion et imposture. Paris: Denoël, 2007.

. Le nouveau national-populisme. Paris: CNRS Éditions, 2008.

VOEGELIN, Erich. Die politischen Religionen. Wien: Bermann-Fischer, 1938.

Tradução

Rodrigo Seixas

Doutorando e mestre em Estudos Linguísticos pela Universidade Federal de Minas Gerais (UFMG), Brasil.

Forma de citação sugerida:

ANGENOT, Marc. A retórica da qualificação e as controvérsias de rotulagem. Tradução: Rodrigo Seixas. EID\&A - Revista Eletrônica de Estudos Integrados em Discurso e Argumentação, llhéus, n. 18, p. 151-170, abr.2019. DOI dx.doi.org/10.17648/eidea-18-2283. 